\title{
First Polish Conference on Sarcoidosis
}

The authors declare no financial disclosure

„Sarcoidosis has many names” (,Sarkoidoza niejedno ma imię") the First Polish Conference on Sarocidosis, Ciechocinek, 25 April 2015 has documented this original term. The Conference was organized by the Clinical Diagnostic Assembly of Polish Respiratory Society and the Warsaw Section of Polish Society of Clinical and Experimental Immunology. The importance of this event was supported by the participation of leading Polish experts in sarcoidosis and a large audience including 70 medical doctors and 30 patients from the „Sarco-Association”. All participants pointed to the urgent need to prepare national guidelines for the diagnosis, management and treatment of sarcoidosis.

The first lectures focused on recent advances in the treatment of this disease (prof. D. Ziora, prof. T. Płusa, dr M. Piotrowska). The theoretical background of treatment, the international guidelines and the indication for lung transplantation were presented. Recent progress in the treatment of sarcoidosis seems to copy biological and personalized regimens used in the other diseases. The need for approval for the use of anti- $\mathrm{TNF} \alpha$ in Poland was emphasized.

In the next part of the clinical session the role of diagnostic methods was presented. Assoc. Prof. W. Piotrowski referred to inadequate use of HRCT in the management of sarcoidosis. Assoc. Prof. T. Przybyłowski in his comprehensive lecture emphasized the role of pulmonary function tests and exercise tests in the diagnosis and management of this disease. The value of the detection of obstruction in pulmonary function tests, appropriate interpretation of diffusing capacity measurement, and the indication to exercise tests were discussed. In the next presentations it was pointed out that in most cases histopathological confirmation of sarcoidosis is needed. Prof. R. Krenke, dr Ł. Kasper, and dr M. Jakubiak presented the role of modern endoscopic techniques and cytological methods as diagnostic procedures. Particular attention was given to the new possibility of cytological samples processing by the use of cell blocks.

Diagnosis and treatment of extrapulmonary sarcoidosis remains controversial. Sarcoidosis of the nervous system was discussed by pulmonologist dr A. Kempisty and also by neurologist Assoc. Prof. M. Gaweł. These two lectures were followed by the presentation of muscular sarcoidosis by dr. M. Lipowska. These three presentations showed the importance of appropriate and quick diagnosis of the involvement of the nervous system by granulomas and the need for intensive treatment as nervous system sarcoidosis may be fatal.

Regarding the etiopathogenesis of sarcoidosis, prof. A. Dubaniewicz revealed the latest results of molecular studies on the role of receptors Fc $\gamma \mathrm{R}$, encoded by polymorphic FCGRI-III genes, in the context of 'danger theory'. The recently discovered complicated molecular mechanisms of the immune reactions were discussed by prof. J. Malejczyk and dr. E. Gładkowska- Mrówka. All speakers indicated the possible etiological role of microbes in sarcoidosis. Assoc. Prof. B. Szponar

Address for correspondence: Prof. Joanna Domagała-Kulawik, MD, PhD, Department of Pneumonology Medical University of Warsaw, ul. Banacha 1a, 02-07 Warsaw, e-mail: domagalakulawik@gmail.com

DOI: 10.5603/PiAP.2015.0054

Received: 7.05 .2015

Copyright (C) 2015 PTChP

ISSN 0867-7077 
presented a recent view on the role of lung microbiom and dr A. Kempisty initiated a discussion on the role of the detection of latent tuberculosis in the course of sarcoidosis.

Tobacco smoking is the main risk factor in most lung diseases. In sarcoidosis the suggested protective role of nicotine has been investigated for many years without any evidence in support. The debate in this field was conducted by prof. J. Domagała-Kulawik and dr E. Puscinska (pro and contra).

During the third part of the conference the results of original studies were presented and discussed by the authors.
It should be mentioned that uniquely not only medical doctors but also patients suffering from sarcoidosis participated in this conference. They directed many questions to the experts and received many useful clarifications regarding this life-long disease.

The First Polish Conference will not be the last meeting devoted to such a mysterious disease. Prof. A. Dubaniewicz is pleased to announce the next WASOG Meeting in Gdańsk, on 3-4 ${ }^{\text {th }}$ June 2016.

\section{Conflict of interest}

The authors declare no conflict of interest. 